\title{
Análise de aspectos sociocientíficos em livros didáticos de química para a segunda e terceira séries do ensino médio
}

\author{
João Paulo Stadler*, Mariana da Silva Azevedo**
}

\section{Resumo}

Investigar diferentes possibilidades a partir do emprego do livro didático em sala de aula é fundamental quando se reconhece a importância desse recurso didático, devido à ampla distribuição promovida pelo Programa Nacional do Livro Didático (PNLD). A abordagem de Aspectos Sociocientíficos (ASC), dentre as várias concepções de ensino de Química, utiliza a contextualização com base em temas socialmente relevantes mobilizados pela discussão de controvérsias e pautadas no conhecimento científico. Assim, investigar a presença de ASC nos livros didáticos de Química pode auxiliar os professores a empregar essa concepção de ensino. Esta pesquisa foi centrada na análise dos livros de Química destinados à segunda e terceira séries do Ensino Médio aprovados pelo PNLD. A metodologia empregada foi a análise de conteúdo baseada nos indicadores: tema global, presença de controvérsia e critérios de relevância para classificar os textos em potenciais promotores de discussões sociocientíficas. Posteriormente, foi delimitado o tipo de abordagem e o tipo de controvérsia apresentados. Em geral, a análise dos livros da segunda série do ensino médio apresentou poucos fragmentos com potencial de abordagem ASC. Além disso, é possível perceber que a maioria das obras têm algum potencial de fomentar discussões ASC em sala de aula, embora os livros não tragam todos os elementos necessários para que a discussão da controvérsia se desenvolva, fato que dependerá dos professores e alunos. Como o esperado, a obra com maior incidência, ainda que não na maioria de suas unidades de contexto, é a obra Química Cidadã, por ser construída nessa abordagem.

Palavras-chave: Aspectos sociocientíficos; Livro didático; PNLD; Ensino de Química.

- Mestre e doutorando em Ensino de Ciências e Matemática pelo Programa de Pós-Graduação em Formação Científica, Educacional e Tecnológica da Universidade Tecnológica Federal do Paraná - campus Curitiba. Professor do Colegiado de Química do Instituto Federal de Educação, Ciência e Tecnologia do Paraná - campus Palmas. E-mail: joao.stadler@ifpr.edu.br.

* Doutora em Ciências pelo Centro de Energia Nuclear na Agricultura da Universidade de São Paulo. Professora do Colegiado de Ciências Biológicas do Instituto Federal de Educação, Ciência e Tecnologia do Paraná - campus Palmas. E-mail: mariana.azevedo@ifpr.edu.br.

Recebido em: 01/09/2020; Aceito em: 27/08/2021

https://doi.org/10.5335/rbecm.v4i2.11605

http://creativecommons.org/licenses/by-nc-nd/4.0

ISSN: 2595-7376 


\section{Introdução}

Entende-se que a área de Ciências da Natureza e, dentro dela, o ensino de Química deve promover a construção de conhecimentos de forma contextualizada e a preparação dos estudantes para a argumentação, a tomada de decisão e a proposição de alternativas frente a temas contextualizados (BRASIL, 1996; 2017).

Dentre as diversas concepções e metodologias que permitem atingir tais ideais, a abordagem de aspectos sociocientíficos (ASC) se mostra promissora por tratar dos temas e conteúdos visando a argumentação e a tomada de decisão por meio da proposição e análise de argumentos motivadas por controvérsias inclusas nos vários contextos a serem estudados, sem o apagamento do conteúdo científico no processo educativo (SANTOS; MORTIMER, 2001; PÉREZ; CARVALHO, 2012). Esses autores concluem que os pontos positivos observados na abordagem de ASC nas aulas foram a maior participação dos alunos e o desenvolvimento de habilidades e competências voltadas à argumentação e tomada de decisão. Por outro lado, as principais dificuldades encontradas indicam a falta de segurança ao abordar controvérsias em sala de aula, a dificuldade dos alunos em empreenderem os processos argumentativos, o conflito com as ideias tradicionais do ensino e o uso (quase) exclusivo do livro didático.

Colocando em foco o emprego do livro didático, desde Fracalanza (1992) até estudos atuais como o de Delizoicov, Angotti e Pernambuco (2018), observa-se a dependência dos professores em relação a esse recurso didático, em especial em relação à sequência dos conteúdos. Segundo Fracalanza (1992), a baixa qualificação dos professores e as diferentes clientelas que passaram a frequentar a escola levaram à adoção dos livros didáticos como um parâmetro nivelador dos conteúdos planejados e das atividades abordadas. Os pontos problemáticos da dependência em relação aos livros didáticos são a excessiva preocupação com a memorização de fórmulas e a utilização dos experimentos como prova de teoria, além da fragmentação do conteúdo (FRACALANZA, 1992). Apesar da adoção de diretrizes para a organização dos livros didáticos, Neto e Fracalanza (2003) constataram que os materiais destoam muito das recomendações legais. Além disso, o livro didático, em alguns casos, é o único contato da parcela mais carente da população com os conteúdos científicos, devido à falta de outras políticas que assegurem o acesso de materiais didáticos diversificados.

Este artigo traz a continuação das análises apresentadas anteriormente (OS AUTORES), realizadas no âmbito do Laboratório Dinâmico e Interdisciplinar 
para o Ensino de Ciências (LADIEC) do campus Palmas, do Instituto Federal de Educação, Ciência e Tecnologia do Paraná. Seu objetivo é expor os resultados da investigação de potencialidades para a abordagem de ASC por meio dos livros didáticos de Química destinados à segunda e terceira séries do Ensino Médio, com o intuito de auxiliar os professores na escolha de materiais que possam auxiliar no emprego desta abordagem.

\section{Apontamentos sobre a presença de aspectos sociocientíficos em materiais de larga escala}

Santos (2002) apresenta a controvérsia, a significação social e a relação com a ciência e a tecnologia como dimensões que compõe a abordagem sociocientífica, o que indica que a necessidade de discutir os conhecimentos científicos deve ser promovida pelo conflito entre posicionamentos em torno de uma controvérsia relevante para os estudantes. A relevância confere sentido à discussão e permite que os estudantes teçam explicações e fundamentem suas decisões com base em sua vivência (PEREZ; CARVALHO, 2012). Esse movimento possibilita o desenvolvimento de competências e habilidades argumentativas que devem ser articuladas à aquisição do conhecimento científico. O objetivo, então, de organizar as ações educativas por meio da abordagem de ASC é a possibilidade de incentivar a discussão que permita a ressignificação dos conteúdos por meio da controvérsia que pode surgir do contexto social, ou da contextualização trazida pelos professores, ou pelos materiais didáticos (SANTOS; MORTIMER, 2009).

Diante da possibilidade de utilizar o livro didático como fonte de contextualização para a discussão, considerando sua importância no processo educativo discutida acima e reconhecendo que o PNLD busca a distribuição de materiais em larga escala, é essencial que os elementos nele presentes sejam relevantes para a população em geral. Sobre temáticas que são significantes em exames de larga escala, Merryfield (1991 apud SANTOS 2002) apresenta os temas globais que foram adotados neste estudo como indicadores de relevância para abordagem ASC. O autor descreveu estes temas como problemas regionais e globais que versam sobre temas ambientais; saúde e população; questões econômicas; transporte e comunicação; alimentos e fome; energia e questões militares, cuja característica é a frequente divulgação na mídia e o interesse da maioria da população. Na primeira parte do estudo (OS 
AUTORES) foram estabelecidos outros temas de relevância complementares aos de Merryfield (1991 apud SANTOS, 2002): natureza da ciência, ao discutir os processos de construção do conhecimento científico; e temas sociais, quando a controvérsia não está centrada em questões econômicas.

Ainda sobra a abordagem temática de conteúdos escolares, a forma como o tema é articulado à prática docente e conduzido durante o processo de ensino e aprendizagem pode ocorrer de diferentes formas que podem ser complementares. Santos (2002) e Halmenschlager e Delizoicov (2017) descrevem os tipos de abordagem na concepção, sendo: de forma temática, quando se emprega um assunto geral para suscitar as discussões fomentadas pelo conhecimento científico; de forma pontual, quando os conceitos estudados estão intimamente ligados a um fato ou fenômeno cotidiano específico; e descritos de forma concomitante ao conteúdo, por meio de questionamentos dirigidos acerca do tema. Tais modos permitem, então, a inclusão dos temas como forma de significação dos conteúdos e estímulo à argumentação com o objetivo de possibilitar a formação cidadã.

Além da característica temática, outros critérios de relevância podem ser utilizados para identificar potenciais questões sociocientíficas (FERNANDES-SOBRINHO, 2014) e foram utilizados neste artigo de forma complementar aos temas globais. Foram descritos 10 critérios: ter base na ciência, frequentemente em áreas que estão nas fronteiras do conhecimento científico; envolver a formação de opiniões e a realização de escolhas no nível pessoal e social; ser frequentemente divulgada pela mídia com destaque a aspectos baseados nos interesses dos meios de comunicação; lidar com informações incompletas sejam elas de evidências científicas incompletas ou conflitantes ou de lacunas nos registros; lidar com problemas locais e globais e suas estruturas sociais e políticas; envolver a análise de custo e benefício na qual os riscos interagem com valores; envolver considerações sobre desenvolvimento sustentável; envolver valores e raciocínio ético; requerer algum entendimento de probabilidade e risco; e ser frequentemente pontuais durante a transição de uma vida.

Outra maneira de caracterizar a controvérsia empregada na abordagem ASC foi apresentada por Stadler (2015), que identificou em exame de larga escala a presença de dois tipos de controvérsia: a tomada de decisão, quando a questão controvertida requer que o estudante escolha a melhor alternativa para a solução de um problema ou tome partido frente a explicações controversas sobre o mesmo tema, por exemplo; e a justificativa de escolha/decisão, quando a tarefa consiste em 
argumentar sobre assuntos controversos que justifiquem ou critiquem uma decisão ou escolha feita por outros. A tipificação das controvérsias foi posteriormente complementada (OS AUTORES), analisando livros didáticos e identificando mais dois tipos de controvérsia: o debate, quando a ação não envolve a tomada de decisão, mas envolve apresentação e reflexão sobre pontos de vista; e a prática social, na qual os alunos devem mobilizar outras pessoas por meio de campanhas, entrevistas e outras atividades. Em conjunto com os temas globais identificados (OS AUTORES), estes novos tipos foram considerados na segunda parte da análise aqui apresentada.

\section{Encaminhamentos metodológicos}

Assim como realizado no artigo que avaliou as obras destinadas à primeira série do ensino médio (OS AUTORES), esta pesquisa é uma análise bibliográfica de caráter qualitativo (GIL, 2010), pautada na análise de conteúdo (BARDIN, 2011) e empreendida em três etapas: pré-análise, que consiste na escolha do corpus e da elaboração dos indicadores de análise; análise, na qual a técnica é aplicado ao corpus; e na síntese dos resultados, na inferência e na interpretação.

A etapa de pré-análise, que denominamos de análise preliminar das obras, consistiu no contato inicial com os livros para estabelecer como se daria a comparação entre os elementos do corpus que foram analisados. Nessa fase é realizada a leitura superficial (dinâmica) do livro completo a fim de identificar como a obra é dividida e, finalmente, como as obras poderiam ser comparadas em função dessa divisão. Além disso, nesta primeira etapa, foram elencados os indicadores da análise:

a) corpus: os livros didáticos de Química disponibilizados pelo PNLD 2018, destinados à segunda e terceira séries do Ensino Médio:

i) Livro 1: Química (REIS, 2016);

ii) Livro 2: Química (MORTIMER; MACHADO, 2017);

iii) Livro 3: Química Cidadã (SANTOS; MÓL, 2016);

iv) Livro 4: Ser Protagonista - Química (LISBOA, 2016);

v) Livro 5: Química (CISCATO et al., 2016);

vi) Livro 6: Vivá - Química (NOVAIS; ANTUNES, 2016).

b) unidade de registro: palavra;

c) regra de enumeração: presença;

d) critério de categorização: semântico; 
e) indicadores: controvérsia, temas globais, conteúdo científico e critérios de relevância social de abordagem sociocientífica, sendo:

i) Controvérsia: o fragmento de texto deve trazer elementos que permitam a discussão de dois pontos de vista conflitantes para a resolução de um problema;

ii) Temas globais: Merryfield apresentou como indicadores de relevância social em documentos de grande escala os seguintes elementos: temas ambientais; saúde e população; questões econômicas; transporte e comunicação; alimentos e fome; energia; e questões militares (1991 apud SANTOS, 2002). Esses temas seriam, em tese, de conhecimento de todos os cidadãos em razão de sua importância para a vida.

iii) Conteúdo científico: este indicador é citado como elemento essencial para a abordagem de ASC, mas considera-se aqui que estão sempre presentes, uma vez que as obras são livros didáticos.

iv) Critérios de relevância social de abordagem sociocientífica: apresentados por Fernandes-Sobrinho (2014), esses elementos conferem à abordagem a relevância social necessária para que as pessoas se engajem em discuti-las. São eles: 1) ter base na ciência, frequentemente em áreas que estão nas fronteiras do conhecimento científico; 2) envolver a formação de opiniões e a realização de escolhas no nível pessoal e social; 3) ser frequentemente divulgada pela mídia com destaque a aspectos baseados nos interesses dos meios de comunicação; 4) lidar com informação incompleta, seja ela de evidência científica incompleta ou conflitante ou de lacunas nos registros; 5) lidar com problemas locais e globais e suas estruturas sociais e políticas; 6 ) envolver a análise de custo e benefício, na qual os riscos interagem com valores; 7) envolver considerações sobre desenvolvimento sustentável; 8) envolver valores e raciocínio ético; 9) requerer algum entendimento de probabilidade e risco; e 10) ser frequentemente pontual durante a transição de uma vida.

f) categorias: com potencial para abordagem de ASC ou sem potencial para abordagem de ASC.

No segundo momento, que aqui chamamos de análise aprofundada das obras, as divisões estabelecidas na etapa anterior são lidas em profundidade para que seja 
feita sua categorização com base nos indicadores elencados. O registro da análise é composto por uma rápida descrição do fragmento, acompanhada da identificação dos elementos estabelecidos para classificá-las quanto à abordagem de ASC. Nesta etapa, cada fragmento foi incluído em tabela de análise (que, por questões de espaço foram anexadas como material complementar) para serem classificados como fragmentos com potencial para a abordagem de ASC aqueles que apresentam: relação com um dos temas globais; uma controvérsia; e ao menos um dos critérios de relevância social de abordagem sociocientífica.

A terceira etapa consiste na construção dos resultados de análise e é apresentada no próximo item deste artigo. É importante salientar que a análise de conteúdo, mesmo contando com os critérios de caracterização das categorias, depende da interpretação do analista frente aos fragmentos do corpus analisado. Em razão disso, serão apresentados os motivos que levaram à classificação proposta, após as tabelas de apresentação dos resultados da categorização. Quanto às tabelas de categorização, elas são, em analogia, como o caderno de campo ou de laboratório, ou seja, servem de anotação para as observações da pesquisa. Por isso, para a compreensão da análise de modo integral, é interessante combinar a tabela de análise (material complementar) e as sínteses aqui apresentadas.

Ainda, além da categorização com os indicadores propostos, este estudo atribuiu mais duas características àqueles fragmentos que foram classificados com potencial para abordagem de ASC. São eles: o tipo de abordagem (pontual; temática; ou por questionamento), de acordo com o apresentado por Santos (2002); e o tipo de controvérsia (justificativa de escolha ou tomada de decisão), trazido em Stadler (2015) e (OS AUTORES). O objetivo desse movimento foi trazer mais elementos para a caracterização de possíveis práticas sociocientíficas em sala de aula.

\section{Resultados e discussões}

É importante esclarecer que a classificação demanda a construção de uma tabela descritiva de todos os recortes das obras, o que acaba por produzir documentos bastante extensos. Por isso, os resultados serão apresentados de maneira sucinta, com o detalhamento de apenas alguns exemplos, por questão de espaço. Além disso, é importante salientar que a intencionalidade no uso de recursos didáticos está intimamente relacionada à prática docente, por isso indicamos que as obras têm 
potencial para a abordagem de ASC, que dependerá fortemente da maneira como o professor irá empregá-lo em suas aulas.

\section{Análise preliminar}

Essa etapa teve por objetivo identificar possíveis recortes nas obras do corpus para que a categorização possa ser feita em partes para, ao final, caracterizar a obra por completo. A partir da análise preliminar foi possível perceber que, de forma semelhante à análise dos livros destinados à primeira série do ensino médio (OS AUTORES), as obras não possuem estritamente a mesma organização, tornando-se novamente necessária a opção da comparação das obras como um todo, ao invés de compará-las por fragmentos. Assim, as obras foram fragmentadas como relatado abaixo, da mesma forma como foram divididas para a análise dos livros da primeira série do ensino médio (OS AUTORES):

- O livro 1 (REIS, 2016) foi fragmentado em: seção de abertura da unidade; seção de abertura do capítulo; seção de conteúdo e seção de encerramento do capítulo.

- O livro 2 (MORTIMER; MACHADO, 2017 foi fragmentado em: seção de abertura do capítulo e seção de conteúdo.

- O livro 3 (SANTOS; MÓL, 2016) foi fragmentado em seção de abertura, seção de conteúdo e seção de encerramento do capítulo.

- O livro 4 (LISBOA, 2016) foi dividido em: seção de abertura da unidade; seção de abertura do capítulo; seção de conteúdo e seção de encerramento do capítulo (subdividida).

- O livro 5 (CISCATO et al., 2016), por sua vez, apresenta estrutura bastante singular quando comparado com às outras obras, pois traz capítulos divididos em temas, em contraste a unidades e capítulos. Sendo assim, a obra foi fragmentada em: seção de abertura do capítulo (subdividida), seção de conteúdo do tema, seção de encerramento do tema e seção de encerramento do capítulo. É importante sempre atentar-se para a relação entre os capítulos dessa obra com as unidades das demais (que possuem) e dos temas com os capítulos.

- Finalmente, o livro 6 (NOVAIS; ANTUNES, 2016) foi fragmentado em seção de abertura da unidade; seção de abertura do capítulo; seção de conteúdo, seção de encerramento do capítulo e seção se encerramento da unidade. 
Como indicado em maiores detalhes em (OS AUTORES), a categorização considerou, primeiramente, cada fragmento e, posteriormente, foi realizada a caracterização da obra como um todo. Somente após a análise aprofundada das obras procedeu-se com a comparação entre os livros.

\section{Análise aprofundada}

Nessa etapa foi feita a busca, em cada unidade de contexto e suas subdivisões, dos indicadores empregados para caracterizar a potencialidade de abordagem de aspectos sociocientíficos. Nos quadros é feita uma breve descrição do fragmento (com a indicação de página das ocorrências principais), acompanhada da descrição do tema global (SANTOS, 2002), da controvérsia, com a tipificação (STADLER, 2015), o critério de relevância social de abordagem sociocientífica (SOBRINHO-FERNANDES, 2014), a tipificação da abordagem, caso contenha todos os elementos precedentes (HALMENSCHLAGER; DELIZOICOV, 2017; SANTOS, 2002) e, se necessário, comentários do analista. É importante salientar que a tipificação da abordagem não é um indicador, mas é um dado importante para a inferência sobre como as atividades com potencialidades para a abordagem de ASC poderiam ser trabalhadas em sala aula.

Em relação aos temas globais de Merrifield (SANTOS, 2002), sua escolha refere-se ao fato de que as obras promovidas pelo PNLD, assim como os exames de larga escala (nos quais os temas foram estudados), são destinados a uma população muito heterogênea, de modo que é necessário buscar elementos de relevância social que sejam o mais abrangente possível. A questão da relevância é corroborada pelos critérios de relevância social na abordagem sociocientífica (FERNANDES-SOBRINHO, 2014), que são empregados na caracterização da controvérsia em temos de relevância social. Em relação ao critério de relevância que envolve problemas locais e globais, considerou-se que os problemas locais se referiam a problemas com impacto em certa região (não sendo necessariamente a região de residência dos consumidores da obra) e problemas globais eram relacionados a problemas reconhecidos em escala global.

Para realizar a tipificação da controvérsia em tomada de decisão, avaliação / justificativa de escolha (STADLER, 2015), debate e prática social (os últimos incluídos em função do resultado da etapa anterior), foram considerados que no primeiro caso, deve-se escolher entre alternativas possíveis para a solução de problemas ou escolher um lado de uma discussão para seguir, enquanto que no segundo caso, deve-se usar 
valores e análises de custo benefício para avaliar ou justificar uma decisão tomada por outrem (STADLER, 2015). Para os debates, considerou-se questões que não tivessem uma pergunta norteadora, apenas a instrução de debater um assunto e, em relação à prática social, foram elencadas nessa categoria atividades que envolviam ações com outros grupos, além da sala de aula, ou apresentação de seminários para os colegas.

A seguir serão caracterizadas, qualitativamente, todas as unidades de contexto de cada obra, de acordo com a sistematizado nos quadros do documento complementar. Na indicação das páginas é colocada a página inicial da unidade de contexto, que pode se estender por várias páginas.

\section{Livros da segunda série do ensino médio}

Inicialmente, foi feita a análise aprofundada de todos os livros da segunda série do ensino médio, como descrito a seguir.

Livro 1: Reis (2016)

O quadro 1 sumariza as principais características das seções do livro 1 frente aos critérios de categorização, baseado nos exemplos de fragmentos com características de ASC retirados do material:

- Página 62: na seção de abertura da unidade 2, os alunos são provocados a discutir as ações humanas frente a economia de água, com questionamentos como "Por que não economizamos água e evitamos polui-la" e "Por que não elaboramos um código florestal que proteja os mananciais e investimos na despoluição e no tratamento de esgoto". Essa atividade foi considerada potencialmente ASC do tipo debate por meio de questionamentos, pois mobiliza discussões sobre realização de escolhas baseadas em valores, está frequentemente divulgada na mídia, envolve problemas locais e globais, necessita da avaliação de custo benefício de viés sustentável, que deve propor ideias a serem realizadas ainda nessa geração.

- Página 139: No trabalho em equipe do box "De onde vem... para onde vai?" Os alunos são levados a debater sobre o valor social dos diamantes em relação ao seu valor comercial e ao custo social em razão da exploração de trabalhadores. Por isso, foi considerada uma atividade potencial do tipo debate por meio de questionamentos que envolvem formação de opinião e realização de escolhas, baseadas em valores, que se destina a avaliar o custo benefício desse problema que é divulgado pela mídia. 
- Na abertura e no box "Retomando a notícia" do capítulo 11, por meio do texto "Tecnologia, consumo e dor", os alunos são levados a discutir como os trabalhadores das minas são explorados para possibilitar os luxos tecnológicos e sobre o motivo dessas informações nas Páginas 264 e 269 não serem amplamente divulgadas na mídia. É uma atividade do tipo debate por meio de questionamentos. A atividade envolve a formação de opiniões, pautada em valores, baseada em avaliação de custo benefício e de risco, acerca de um problema local.

- Página 271: Na atividade de trabalho em equipe no box "De onde vem... para onde vai?" Do capítulo 11, os alunos são estimulados a discutir sobre as vantagens e desvantagens da reciclagem de alumínio e as implicações sociais desse processo. Por ser uma atividade que envolve a formação de opinião, pautada tanto no conhecimento científico, baseada em valores sobre esse problema local de sustentabilidade, o qual é amplamente divulgado na mídia, esse trecho foi classificado como uma atividade com potencial ASC do tipo debate por questionamentos.

Quadro 1: Análise aprofundada do Livro 1

\begin{tabular}{|c|c|c|}
\hline \multirow{2}{*}{$\begin{array}{l}\text { Organização do } \\
\text { Livro }\end{array}$} & \multicolumn{2}{|c|}{$\begin{array}{l}\text { As aberturas das unidades são facilmente relacionadas com temas ambientais, mas não } \\
\text { apresentam elementos para a discussão ASC nos textos. Algumas podem ser complemen- } \\
\text { tadas para possibilitar tal discussão. }\end{array}$} \\
\hline & \multicolumn{2}{|c|}{$\begin{array}{l}\text { As unidades de abertura do capítulo, exceto no caso no capítulo 1, estão relacionadas a te- } \\
\text { mas globais como contextualização, mas em geral não apresentam controvérsia, observada } \\
\text { apenas no capítulo } 11 \text { sobre condições de trabalho em minas. }\end{array}$} \\
\hline $\begin{array}{l}\text { Texto de } \\
\text { Conteúdo }\end{array}$ & \multicolumn{2}{|c|}{$\begin{array}{l}\text { O conteúdo é apresentado em texto corrido com alguns questionamentos sobre o cotidiano, } \\
\text { mas não aborda ASC. }\end{array}$} \\
\hline \multirow{4}{*}{$\begin{array}{l}\text { Conteúdo dos } \\
\text { boxes }\end{array}$} & $\begin{array}{l}\text { Foi notícia: Todos os capítulos têm seção de } \\
\text { abertura com texto jornalístico facilmente re- } \\
\text { lacionado relacionados a Temas Globais, Te- } \\
\text { mas Sociais ou Questões econômicas. Ape- } \\
\text { nas o capítulo } 11 \text { aborda ASC, apresentado } \\
\text { por meio de questionamentos }\end{array}$ & $\begin{array}{l}\text { De onde vem... Para onde vai?: apresenta- } \\
\text { ção de matérias-primas, processos de ob- } \\
\text { tenção e uso de substâncias. Em geral não } \\
\text { aborda ASC (exceto capítulo } 2 \text { ) }\end{array}$ \\
\hline & $\begin{array}{l}\text { Retomando a notícia: apesar de ligadas aos } \\
\text { temas ambientais, não abordam ASC, exceto } \\
\text { nos capítulos } 5 \text { e } 11 \text {, as quais foram feitas por } \\
\text { meio de questionamentos }\end{array}$ & $\begin{array}{l}\text { Saúde e sociedade: relação da Química } \\
\text { com a saúde e a sociedade, mas não abor- } \\
\text { da questões controversas }\end{array}$ \\
\hline & $\begin{array}{l}\text { Experimentos: Não presenta caráter de inves- } \\
\text { tigação, nem aborda questionamentos ASC }\end{array}$ & $\begin{array}{l}\text { Compreendendo o Mundo: Em todos os ca- } \\
\text { pítulos foram trazidas questões ao final com } \\
\text { ASC, mas que não podem ser discutidas } \\
\text { em sua totalidade com o conteúdo do livro }\end{array}$ \\
\hline & Cotidiano do químico: Não aborda ASC & $\begin{array}{l}\text { Curiosidade: Não apresenta questões con- } \\
\text { troversas }\end{array}$ \\
\hline Exercícios & \multicolumn{2}{|c|}{$\begin{array}{l}\text { Somente de exames de vestibulares / Enem, apresentados em vários momentos do capítu- } \\
\text { lo. Consideramos que não aborda ASC }\end{array}$} \\
\hline
\end{tabular}

Fonte: autoria própria, a partir de Reis (2016) 
Diante dos resultados das unidades de contexto é possível afirmar que o livro 1 (REIS, 2016) apresenta elementos relacionados a ASC, em sua maioria abordados por questionamentos que não são tratados no livro de forma completa, ou seja, o livro, sozinho, não contém todos os elementos necessários para uma discussão, os quais deverão ser trazidos de outros meios. Todos os casos observados foram do tipo debate, que dependerá muito da condução da atividade pelo professor para que essa seja considerada efetivamente ASC. Também foi possível notar que o volume 2 apresenta menos potencial ASC que o primeiro (OS AUTORES).

\section{Livro 2: Mortimer e Machado (2017)}

O quadro 2 sumariza as principais características das seções do livro 2 frente aos critérios de categorização. A partir da leitura aprofundada da obra, foi possível localizar apenas um exemplo de atividade potencialmente sociocientífica na atividade "Projeto" do capítulo 2 (p. 59). Nessa atividade, os alunos deveriam debater sobre vantagens e desvantagem das fontes de energia mais comuns focando em impactos sociais e ambientais. Desse modo, a atividade foi classificada como um debate por meio de questionamentos que envolvem temas ambientais, questões econômicas e temas sociais (corroborando com a sugestão desse novo tema). As discussões versariam sobre a formação de opiniões, baseadas em valores e no conhecimento científico sobre um problema local, divulgado pela mídia, de cunho sustentável, que envolve a análise de custo-benefício.

\section{Quadro 2: Análise aprofundada do Livro 2}

\begin{tabular}{|c|c|c|}
\hline \multirow{2}{*}{$\begin{array}{l}\text { Organização do } \\
\text { Livro }\end{array}$} & \multicolumn{2}{|c|}{$\begin{array}{l}\text { A divisão dos capítulos é feita baseada fortemente nos conceitos científicos abordados, não } \\
\text { apresentando laços estreitos com temas ambientais (com exceção dos capítulos } 1 \text { e } 2 \text { ). }\end{array}$} \\
\hline & \multicolumn{2}{|c|}{ Apenas no projeto do capítulo 2 foi possível encontrar elementos para abordagem ASC } \\
\hline Texto de Conteúdo & \multicolumn{2}{|c|}{$\begin{array}{l}\text { O conteúdo é apresentado em formato de texto corrido, complementado pelas informa- } \\
\text { ções dos boxes, sem questionamentos }\end{array}$} \\
\hline \multirow{5}{*}{$\begin{array}{l}\text { Conteúdo dos } \\
\text { boxes e atividades }\end{array}$} & Além da Química: não aborda ASC & Exercícios: Não aborda ASC \\
\hline & Um pouco de História: não aborda ASC & Questões de exames: não aborda ASC \\
\hline & Cálculos: não aborda ASC & $\begin{array}{l}\text { Reflexão: dificilmente trazem questões com } \\
\text { ASC }\end{array}$ \\
\hline & $\begin{array}{l}\text { Na internet: (não foi citado, por não ofere- } \\
\text { cer questões ASC) }\end{array}$ & Questões preliminares: não aborda ASC \\
\hline & $\begin{array}{l}\text { Investigação: dificilmente trazem questões } \\
\text { ASC }\end{array}$ & $\begin{array}{l}\text { Projeto: dificilmente trazem questões ASC } \\
\text { (apenas capítulo 2) }\end{array}$ \\
\hline
\end{tabular}

Fonte: autoria própria, a partir de Mortimer e Machado (2017) 
Desse modo, tomando por base a análise nas descrições e no Quadro 2, foi possível perceber que a obra não traz os elementos necessários para as discussões, apenas propondo as atividades. O livro apresenta abordagem fortemente marcada pelo estudo centrado no conceito científico, não explorando em profundidade questões concernentes ao ASC. E que, como no caso anterior, há menos exemplos de atividades potencialmente sociocientíficas que no volume 1 (OS AUTORES).

\section{Livro 3: Santos e Mól (2016)}

O quadro 3 sumariza as principais características das seções do livro 3 frente aos critérios de categorização. Considerando os novos temas globais e tipos de abordagem, a análise do volume dois dessa coleção apresentou os seguintes elementos com potencialidade para discussão ASC:

- Páginas 23 e 36: O tópico 5 do texto de conteúdo do capítulo 1 é destinado à discussão sobre os impactos sociais e ambientais do consumismo e a necessidade de se pensar em consumo consciente. Assim como em casos do primeiro volume, esse tipo de ocorrência é considerado como apresentando abordagem temática, por abranger várias páginas e tópicos. Ao mobilizar todos os critérios de referência, pois durante o texto são postos questionamentos e provocações que levam à formação de opiniões sobre um tema divulgado e de caráter sustentável acerca de análise de risco e de custo benefício calcadas em valores e no conhecimento científico. As discussões do capítulo são retomadas em debates por questionamentos nos boxes participação cidadã e ação e cidadania.

- Página 45: $\mathrm{Na}$ atividade Tomada de decisão do capítulo 2, os alunos são convidados a discutir e tomar decisão acerca da autorização da venda de produtos químicos por autônomos. Por envolver a tomada de decisão, pautada na análise de risco e custo benefício, essa atividade foi considerada como uma tomada de decisão por questionamento.

- Páginas 100 e 106: No capítulo 3, novamente encontra-se um tópico do texto de conteúdo que, com o auxílio das atividades "Participação cidadã" e "Ação e cidadania" promovem a discussão ASC temática, por questionamentos e pontual. Nesse caso, os alunos são estimulados a debater sobre temas voltados à alimentação, dieta e hábitos alimentares, nas quais são mobilizados todos os critérios. 
- Página 172: Nos boxes "Tomada de decisão" e "Questão sociocientífica" é abordado o tema Natureza da Ciência. É proposto um debate sobre o papel social dos cientistas (debate por questionamentos) e uma tomada de decisão (por questionamento) sobre a autonomia dos cientistas. A discussão foi considerada como potencial de discussão de ASC, por envolver a formação de opinião acerca dos riscos da autonomia científica.

- Página 246: Na atividade de Participação cidadã (capítulo 6) é proposto um debate sobre os tipos e fontes de combustíveis e suas vantagens e desvantagens. É um tipo de debate por questionamentos, pois requisita a formação de opinião, baseada em valores e no conhecimento científico, que avalia risco e custo benefício acerca de um problema global no âmbito da sustentabilidade, frequentemente divulgado pela mídia.

- Página 278: Ainda no capítulo 5, em outra atividade de "Participação cidadã", os alunos devem discutir sobre o impacto do uso de combustíveis na poluição da atmosfera. Também é um debate por questionamentos, pois requisita a formação de opinião, baseada em valores e no conhecimento científico, que avalia risco e custo benefício acerca de um problema global no âmbito da sustentabilidade, frequentemente divulgado pela mídia. De forma a complementar essa atividade, há os boxes de "Tomadas de decisão" (por questionamentos), que visam decidir se o aquecimento global é ou não é causado por fontes antrópicas; e "Ação e cidadania”, que pretende promover um debate pontual acerca de ações sociais do controle de poluição.

Quadro 3: Análise aprofundada do Livro 3

\begin{tabular}{|c|c|c|}
\hline \multirow{2}{*}{ Organização do Livro } & \multicolumn{2}{|c|}{$\begin{array}{l}\text { Os capítulos não têm abordagem temática porque o contexto social não é trabalhado } \\
\text { de forma contínua }\end{array}$} \\
\hline & \multicolumn{2}{|c|}{$\begin{array}{l}\text { As seções de abertura não abordam ASC. Temas ambientais, questões econômicas e } \\
\text { natureza da ciência foram mais citados }\end{array}$} \\
\hline Texto de Conteúdo & \multicolumn{2}{|c|}{$\begin{array}{l}\text { Todos os capítulos tinham tópicos de relação com temas ambientais. Os capítulos } 1 \text { e } \\
3 \text { tinham possiblidade ASC nos textos }\end{array}$} \\
\hline \multirow{5}{*}{$\begin{array}{l}\text { Conteúdo dos } \\
\text { boxes e atividades }\end{array}$} & Pare e pense: não aborda ASC & $\begin{array}{l}\text { Construção do conhecimento: não } \\
\text { aborda ASC }\end{array}$ \\
\hline & Atividade experimental: não aborda ASC & História da ciência: não aborda ASC \\
\hline & Revisão para a prova: não aborda ASC & Atitude sustentável: não aborda ASC \\
\hline & $\begin{array}{l}\text { Participação cidadã: sempre aborda ASC, } \\
\text { mas não está presente em todos os capítulos }\end{array}$ & $\begin{array}{l}\text { Ação e cidadania: nem sempre aborda } \\
\text { ASC. }\end{array}$ \\
\hline & $\begin{array}{l}\text { Tomada de decisão: sempre aborda ASC, } \\
\text { mas não está presente em todos os capítulos }\end{array}$ & Exercícios: não aborda ASC \\
\hline
\end{tabular}

Fonte: autoria própria, a partir de Santos e Mól (2016). 
Pode-se perceber que a obra se propõe a discutir os ASC e é possível observar a presença de tomadas de decisão, de debates e de justificativas de maneira pontual e por questionamentos, em boxes separados, e um caso de abordagem temática mais abrangente em alguns capítulos. $\mathrm{O}$ texto de conteúdo traz tópicos de contextualização social que poderia suscitar a discussão de ASC, mas não são apresentadas controvérsias no texto, embora elas sejam complementadas pelas atividades do capítulo, enfatizando a abordagem temática.

\section{Livro 4: Lisboa (2016)}

O quadro 4 sumariza as principais características das seções do livro 4 frente aos critérios de categorização. Após a etapa de análise aprofundada, foi novamente verificado o acerte em propor a tipificação debate como melhoria dos tipos considerados inicialmente. Na obra, encontrou-se os seguintes exemplos de atividades ASC:

- Página 27: No box "Química tem história", os alunos são estimulados a debater por meio de questionamentos, razões para justificar os estudos que relacionam a concentração de gás carbônico com o aquecimento global. Nesse sentido, a discussão mobiliza a formação de opiniões baseada em valores e no conhecimento científico, sobre um problema global, divulgado pela mídia, mas que envolve informações incompletas, de cunho sustentável, que envolve a análise de custo-benefício e de risco e deve propor ações para as gerações atuais.

- Página 69: Na atividade do box "Ciência, tecnologia e sociedade", é apresentada uma discussão sobre vantagens, desvantagens e impactos da produção de biodiesel. Por evidenciar a formação de opiniões baseada em valores e no conhecimento científico, sobre um problema global, divulgado pela mídia, de cunho sustentável, que envolve a análise de custo-benefício, foi classificada como uma atividade ASC do tipo debate por questionamentos.

- Página 125: No box "Química tem história", os alunos são convidados a debater sobre o que teria ocorrido se Haber não tivesse encontrado um método para produção mais barata de amônia, indicando a discussão da influência da ciência na sociedade. Por envolver a discussão sobre como o conhecimento científico promove a diminuição do custo, a atividade foi tida como um debate por questionamentos. 
- Página 246: Na seção de abertura do capítulo 13, são apresentados exemplos de aplicação da radiação na saúde e é proposto do debate sobre risco e vantagens em sua utilização. O debate envolve a formação de opiniões, baseada em valores e no conhecimento científico, que avalia o custo-benefício e a análise de risco, indicando uma atividade ASC do tipo debate por questionamento.

Quadro 4: Análise aprofundada do Livro 4

\begin{tabular}{|c|c|c|}
\hline \multirow{2}{*}{ Organização do Livro } & \multicolumn{2}{|c|}{$\begin{array}{l}\text { As unidades são divididas de acordo com o conteúdo químico. As seções de abertura } \\
\text { não trazem elementos que permitem empregar ASC }\end{array}$} \\
\hline & \multicolumn{2}{|c|}{$\begin{array}{l}\text { Os capítulos são organizados de acordo com o conteúdo químico e não favorecem } \\
\text { elementos para discussão ASC, com exceção dos capítulos } 1,6 \text { e } 13\end{array}$} \\
\hline Texto de Conteúdo & \multicolumn{2}{|c|}{$\begin{array}{l}\text { O texto de conteúdo não apresenta questionamentos que levem à discussão ASC } \\
\text { apenas perguntas para averiguar o conhecimento prévio dos alunos }\end{array}$} \\
\hline \multirow{5}{*}{$\begin{array}{l}\text { Conteúdo dos } \\
\text { boxes e atividades }\end{array}$} & Saiba mais: não aborda ASC & $\begin{array}{l}\text { Química tem história: possibilidade ASC } \\
\text { no capítulo } 6\end{array}$ \\
\hline & Você se lembra: não aborda ASC & $\begin{array}{l}\text { Ação e cidadania: embora apresentem } \\
\text { contextualização, não aborda ASC }\end{array}$ \\
\hline & $\begin{array}{l}\text { Química e...: embora apresentem contex- } \\
\text { tualização, não aborda ASC }\end{array}$ & Atividades: não aborda ASC \\
\hline & Enem e Vestibular: não aborda ASC & $\begin{array}{l}\text { Ciência, Tecnologia e Sociedade: apre- } \\
\text { senta contextualização e no capítulo } 1 \\
\text { pode levar à discussão de ASC }\end{array}$ \\
\hline & Atividade experimental: não aborda ASC & $\begin{array}{l}\text { Projeto: não aborda ASC, embora possam } \\
\text { ser considerados contextualizados. }\end{array}$ \\
\hline
\end{tabular}

Fonte: autoria própria, a partir de Lisboa (2016)

Com base nos elementos apresentados acima, conclui-se que, em contraste com o primeiro volume (OS AUTORES), este volume apresentou possibilidades consistentes de iniciar a discussão ASC, embora sejam restritas a questionamentos.

Livro 5: Ciscato et al. (2016)

O quadro 5 sumariza as principais características das seções do livro 5 frente aos critérios de categorização, baseado nos exemplos de fragmentos com características de ASC retirados do material:

- Página 63: Na atividade em grupo da seção de encerramento do capítulo 1 , os alunos são convidados a discutir sobre o abastecimento de água na cidade, meios de diminuir o consumo e possibilidades de obtenção de água, abordando elementos sociais e econômicos como por exemplo: "Como essas famílias contornam essa dificuldade [de falta de água]?” / "Que atitudes 
vocês poderiam tomar para diminuir o consumo de água? / "Quanto essa pessoa gastou para criar essa solução? / “Quais os impactos positivos?”. Essa atividade foi considerada potencialmente ASC do tipo prática social por meio questionamentos, pois envolve a formação de opiniões, baseada em valores e no conhecimento científico, sobre um problema global, amplamente divulgado pela mídia, de cunho sustentável, que envolve a análise de custo-benefício e de risco.

Quadro 5: Análise aprofundada do Livro 5

\begin{tabular}{|l|l|l|}
\hline \multirow{2}{*}{$\begin{array}{l}\text { Organização do } \\
\text { Livro }\end{array}$} & $\begin{array}{l}\text { O livro se organiza por temas de contextualização, a seção de abertura da unidade é } \\
\text { bastante contextualizada, mas nunca controversa. Os trabalhos em grupo são mais } \\
\text { passiveis de ASC }\end{array}$ \\
\cline { 2 - 3 } Os temas são organizados por conteúdos e não permitem abordagem de ASC \\
\hline \multirow{2}{*}{ Texto de Conteúdo } & $\begin{array}{l}\text { O texto de conteúdo não apresenta questionamentos que levem à discussão ASC, } \\
\text { apenas pergunta para averiguar o conhecimento prévio dos alunos }\end{array}$ \\
\hline \multirow{2}{*}{ boxes e atividades } & $\begin{array}{l}\text { Box genérico: sem potencial para } \\
\text { discussão de ASC }\end{array}$ & $\begin{array}{l}\text { Glossário: sem potencial para discussão de } \\
\text { ASC }\end{array}$ \\
\cline { 2 - 3 } & $\begin{array}{l}\text { Atividade prática: sem potencial para } \\
\text { discussão de ASC }\end{array}$ & $\begin{array}{l}\text { Questões para fechamento do tema: sem } \\
\text { potencial para discussão de ASC }\end{array}$ \\
\cline { 2 - 3 } & $\begin{array}{l}\text { Exercícios finais: sem potencial para } \\
\text { discussão de ASC }\end{array}$ & $\begin{array}{l}\text { Atividades em grupo: sempre contextualiza- } \\
\text { das, mas não abordam ASC }\end{array}$ \\
\hline
\end{tabular}

Fonte: autoria própria, a partir de Ciscato et al. (2016)

A partir da análise do segundo volume da obra, foi possível estabelecer que o Livro 5 (CISCATO et al., 2016), apesar de ser organizado por temas e permitir a contextualização do início ao fim dos capítulos, os momentos que teriam maior potencial ASC permitem apenas abordagem pontual. $\mathrm{O}$ conteúdo em si continua desconectado das problemáticas sociocientíficas.

\section{Livro 6: Novais e Antunes (2016)}

O quadro 6 sumariza as principais características das seções do livro 6 frente aos critérios de categorização. Assim como nos casos anteriores, foi possível evidenciar a diminuição do número de ocorrências de atividades com potencial para a discussão sociocientífica. Foram encontradas duas ocorrências complementares (páginas 178 e 181) no box "Viagem no tempo" e na "Questão de encerramento", que também tratavam da questão da síntese da amônia, mas voltada às questões sociais que possibilitaram essa descoberta. Por motivar a discussão acerca da formação de opinião, da análise de riscos em relação ao problema local e global, a atividade foi classificada como debate por questionamentos. 
Quadro 6: Análise aprofundada do Livro 6

\begin{tabular}{|c|c|c|}
\hline \multirow{2}{*}{$\begin{array}{l}\text { Organização do } \\
\text { Livro }\end{array}$} & \multicolumn{2}{|c|}{$\begin{array}{l}\text { A divisão dos capítulos é feita baseada fortemente nos conceitos científicos abordados, } \\
\text { não apresentando laços estreitos com temas globais }\end{array}$} \\
\hline & \multicolumn{2}{|c|}{$\begin{array}{l}\text { Os principais temas foram saúde e população, questões econômicas e temas ambientais. } \\
\text { A possibilidade de ASC foi encontrada nos capítulos } 2 \text { e } 10\end{array}$} \\
\hline Texto de Conteúdo & \multicolumn{2}{|c|}{$\begin{array}{l}\text { O conteúdo é apresentado em formato de texto corrido complementado pelas informações } \\
\text { dos boxes, há questionamentos, nunca controversos }\end{array}$} \\
\hline \multirow{5}{*}{$\begin{array}{l}\text { Conteúdo dos } \\
\text { boxes e atividades }\end{array}$} & Para situá-lo: Não aborda ASC & $\begin{array}{l}\text { Boxes: textos pequenos, sem perguntas, } \\
\text { não aborda ASC }\end{array}$ \\
\hline & $\begin{array}{l}\text { Química: prática e reflexão: Experimentos } \\
\text { e questões voltadas aos conceitos quími- } \\
\text { cos exclusivamente }\end{array}$ & Atividades: questões não abordam ASC \\
\hline & $\begin{array}{l}\text { Viagem no tempo: não aborda ASC, exce- } \\
\text { to no capítulo } 2\end{array}$ & $\begin{array}{l}\text { Testando seus conhecimentos: não aborda } \\
\text { ASC }\end{array}$ \\
\hline & Conexões: não aborda ASC & Resgatando o que foi visto: não aborda ASC \\
\hline & \multicolumn{2}{|c|}{$\begin{array}{l}\text { Atividade de encerramento do capítulo: possibilidades de abordagem ASC nos capítulos } \\
2 \text { e } 10\end{array}$} \\
\hline
\end{tabular}

Fonte: autoria própria, a partir de Novaes e Antunes (2016)

Com base nas indicações feitas, é possível dizer que a obra apresenta poucos elementos relacionados a ASC, por meio de questionamentos que não são tratados no livro de forma completa, pois é requerida etapa de pesquisa externa.

\section{Livros da terceira série do ensino médio}

Em seguida, foi feita a análise aprofundada de todos os livros da terceira série do ensino médio, como descrito a seguir.

Livro 1: Reis (2016)

O quadro 7 sumariza as principais características das seções do livro 1 frente aos critérios de categorização, baseado nos exemplos de fragmentos com características de ASC retirados do material:

- Página 77: Na seção de encerramento da Unidade 1, é proposta uma atividade sobre a escolha energética e o uso de inseticida, que podem levar à discussão controversa com questões como "É possível trocar a frota para carros elétricos? Quais os impactos?” e "É possível deixar de usar inseticidas? Quais os impactos?”. Os alunos são convidados a debater sobre os temas, portanto, o trecho foi considerado como possível promotor de ASC, por meio de questionamentos em atividades de debate, pois envolve a formação de opiniões, 
baseada em valores e no conhecimento científico, sobre um problema global, amplamente divulgado pela mídia e de cunho sustentável, que envolve a análise de custo-benefício.

- Página 96: O box “De onde vem... Para onde vai?" do capítulo 4 da unidade 2 fala sobre a produção de fenol e acetona. Neste é proposta uma atividade de debate sobre vantagens e desvantagens da instalação de um polo petroquímico na cidade, sendo o trecho caracterizado como potencial promotor de discussão ASC por questionamento, pois envolve a formação de opiniões, baseada em valores e no conhecimento científico, além de envolver a análise de custo-benefício e de risco.

- Página 147: Na seção de encerramento da unidade 2 é apresentada uma situação de debate, por meio de questionamento, sobre aspectos sociais e de saúde relacionados ao uso de drogas. Sendo assim, o fragmento foi considerado como sendo uma atividade com potencial de discussão sociocientífica, pois envolve a formação de opiniões, baseada em valores e no conhecimento científico, sobre um problema global, amplamente divulgada pela mídia, que envolve a análise de risco.

- Página 148: Na seção de abertura da unidade 3, os alunos são convidados a debater, por meio de questionamentos, sobre o comportamento humano frente ao consumismo e ao esgotamento de recursos naturais, indicando uma abordagem temática que deverá ser conduzida com o andamento da unidade e envolve a formação de opiniões baseada em valores, sobre um problema global, amplamente divulgado pela mídia, mas que envolve informações incompletas, de cunho sustentável e que envolve a análise de custo-benefício, além de propor ações para as gerações atuais. 
Quadro 7: Análise aprofundada do Livro 1

\begin{tabular}{|c|c|c|}
\hline \multirow{2}{*}{$\begin{array}{l}\text { Organização do } \\
\text { Livro }\end{array}$} & \multicolumn{2}{|c|}{$\begin{array}{l}\text { As aberturas das unidades são facilmente relacionadas com temas ambientais, mas não } \\
\text { apresentam elementos para a discussão ASC nos textos. Algumas podem ser complementa- } \\
\text { das para possibilitar tal discussão. }\end{array}$} \\
\hline & \multicolumn{2}{|c|}{$\begin{array}{l}\text { As unidades de abertura do capítulo, exceto no caso no capítulo } 1 \text {, estão relacionadas a te- } \\
\text { mas globais como contextualização, mas em geral não apresentam controvérsia, observada } \\
\text { apenas no capítulo } 11 \text {, sobre condições de trabalho em minas. }\end{array}$} \\
\hline $\begin{array}{l}\text { Texto de } \\
\text { Conteúdo }\end{array}$ & \multicolumn{2}{|c|}{$\begin{array}{l}\text { O conteúdo é apresentado em texto corrido com alguns questionamentos sobre o cotidiano, } \\
\text { mas não apesenta ASC }\end{array}$} \\
\hline \multirow{4}{*}{$\begin{array}{l}\text { Conteúdo dos } \\
\text { boxes }\end{array}$} & $\begin{array}{l}\text { Foi notícia: Todos os capítulos têm seção de } \\
\text { abertura com texto jornalístico facilmente re- } \\
\text { lacionado relacionados à Energia, Temas So- } \\
\text { ciais, Alimentos e Fome e Saúde e Popula- } \\
\text { ção. A sessão de abertura da unidade } 3 \text { indi- } \\
\text { ca abordagem temática sobre consumismo. }\end{array}$ & $\begin{array}{l}\text { De onde vem... Para onde vai?: apresentação } \\
\text { de matérias-primas, processos de obtenção e } \\
\text { uso de substâncias. Não abordam ASC, exce- } \\
\text { to no capítulo } 4\end{array}$ \\
\hline & $\begin{array}{l}\text { Retomando a notícia: apesar de ligadas aos } \\
\text { temas ambientais, não abordam ASC, exce- } \\
\text { to nos capítulos } 5 \text { e 11, que foram feitas por } \\
\text { meio de questionamentos }\end{array}$ & $\begin{array}{l}\text { Saúde e sociedade: relação da Química com } \\
\text { a saúde e sociedade, mas não são apresenta- } \\
\text { das questões controversas }\end{array}$ \\
\hline & $\begin{array}{l}\text { Experimentos: Não apresenta caráter de in- } \\
\text { vestigação, nem aborda questionamentos } \\
\text { ASC }\end{array}$ & $\begin{array}{l}\text { Compreendendo o Mundo: Em todos os ca- } \\
\text { pítulos foram trazidas questões ao final que } \\
\text { abordam ASC, mas que não podem ser dis- } \\
\text { cutidas em sua totalidade com o conteúdo do } \\
\text { livro, exceto nas unidades } 1 \text { (uso do petróleo) } \\
\text { e } 2 \text { (uso de drogas) }\end{array}$ \\
\hline & Cotidiano do químico: Não aborda ASC & $\begin{array}{l}\text { Curiosidade: Não apresenta questões contro- } \\
\text { versas }\end{array}$ \\
\hline Exercícios & \multicolumn{2}{|c|}{$\begin{array}{l}\text { Somente exercícios de exames vestibulares / Enem, apresentados em vários momentos do } \\
\text { capítulo. Consideramos que não aborda ASC }\end{array}$} \\
\hline
\end{tabular}

Fonte: autoria própria, a partir de Reis (2016)

\section{Livro 2: Mortimer e Machado (2017)}

O quadro 8 sumariza as principais características das seções do livro 2 frente aos critérios de categorização. A partir da leitura aprofundada da obra, foi possível localizar apenas um exemplo de atividade potencialmente sociocientífica na "Atividade reflexão" do capítulo 5 (página 227). Nesta, os alunos devem debater sobre as ações de empresas e do governo para diminuir o consumo de embalagens plásticas e quais as consequências sociais disso. Por isso, o trecho foi considerado potencial promotor de discussão de ASC por meio de questionamentos, pois aborda a formação de opiniões, baseada em valores e no conhecimento científico, sobre um problema global, amplamente divulgado pela mídia, de cunho sustentável e que envolve a análise de custo-benefício e de risco. Desse modo, é possível perceber que a obra não traz os elementos necessários para as discussões, apenas propondo as atividades. 
Quadro 8: Análise aprofundada do Livro 2

\begin{tabular}{|l|l|l|}
\hline \multirow{4}{*}{$\begin{array}{l}\text { Organização do } \\
\text { Livro }\end{array}$} & $\begin{array}{l}\text { Os títulos dos capítulos têm relação contextual com temas ambientais, temas sociais, } \\
\text { alimentos e fome, mas as atividades centram-se nos conhecimentos químicos }\end{array}$ \\
\cline { 2 - 3 } & $\begin{array}{l}\text { Apenas no projeto do capítulo 5, na atividade de reflexão, há indícios de discussão ASC } \\
\text { sobre o consumismo }\end{array}$ \\
\hline \multirow{5}{*}{ Texto de Conteúdo } & $\begin{array}{l}\text { O conteúdo é apresentado em formato de texto corrido, complementado pelas informa- } \\
\text { ções dos boxes, sem questionamentos }\end{array}$ \\
\hline \multirow{3}{*}{$\begin{array}{l}\text { Conteúdo dos } \\
\text { boxes e atividades } \\
\text { Além da Química: sem potencial para } \\
\text { discussão de ASC }\end{array}$} & $\begin{array}{l}\text { Exercícios: sem potencial para discussão de } \\
\text { ASC }\end{array}$ \\
\cline { 2 - 3 } $\begin{array}{l}\text { Um pouco de História: não aborda } \\
\text { ASC }\end{array}$ & $\begin{array}{l}\text { Questões de exames: sem potencial para dis- } \\
\text { cussão de ASC }\end{array}$ \\
\cline { 2 - 3 } & Cálculos: não aborda ASC & $\begin{array}{l}\text { Reflexão: dificilmente trazem questões que abor- } \\
\text { dam ASC, exceto no capítulo 5, sobre consumo }\end{array}$ \\
\cline { 2 - 3 } & $\begin{array}{l}\text { Na internet: (não foi citado, por não } \\
\text { oferecer questões que abordem ASC) }\end{array}$ & $\begin{array}{l}\text { Questões preliminares: sem potencial para } \\
\text { discussão de ASC }\end{array}$ \\
\cline { 2 - 2 } & Projeto: não trazem questões que abordam ASC \\
\hline
\end{tabular}

Fonte: autoria própria, a partir de Mortimer e Machado (2017)

\section{Livro 3: Santos e Mól (2016)}

$\mathrm{O}$ quadro 9 sumariza as principais características das seções do livro 3 frente aos critérios de categorização. Considerando os novos temas globais e tipos de abordagem, a análise do volume três dessa coleção apresentou os seguintes elementos com potencialidade para discussão ASC:

- Páginas 120: No box "Tomada de Decisão" do capítulo 3, os alunos devem tomar partido, e justificar sua escolha, em relação a liberação do uso de determinadas plantas medicinais, mesmo que sua extração em larga escala provoque impactos ambientais. Foi considerado uma atividade promotora de discussão de ASC por meio de questionamentos, do tipo tomada de decisão, pois aborda a formação de opiniões, baseada em valores e no conhecimento científico, sendo amplamente divulgado pela mídia, de cunho sustentável e que envolve a análise de custo-benefício.

- Página 151: No box "Participação cidadã" do capítulo 4, os alunos devem debater sobre a importância e os impactos relacionados a questões sociais, econômicas e ambientais em relação a implementação de uma indústria química na cidade. Foi considerada uma atividade com potencial para discussão de ASC por meio de questionamentos, pois aborda formação de opiniões, baseada em valores e no conhecimento científico, sobre um problema global, de cunho sustentável e que envolve a análise de custo-benefício e de risco. 
- Página 188: No box "Participação cidadã" do capítulo 5, encontra-se uma atividade que prevê que o debate sobre como a ciência, a tecnologia e a sociedade se influenciam mutuamente para o desenvolvimento umas das outras, possibilitando a discussão sobre a relações CTS (Ciência-Tecnologia-Sociedade). Assim, é considerada uma atividade de potencial discussão ASC por meio de questionamentos, pois aborda o conhecimento científico e possui cunho sustentável.

- Página 275: No box “Tomada de decisão" do capítulo 6, os alunos são convidados a debater sobre as vantagens e desvantagens do uso de plásticos, frente aos impactos sociais e ambientais, possibilitando discussões de ASC por meio de questionamentos, pois aborda a formação de opiniões, baseada em valores e no conhecimento científico, sobre um problema global, amplamente divulgado pela mídia de cunho sustentável e que envolve a análise de custo-benefício.

Quadro 9: Análise aprofundada do Livro 3

\begin{tabular}{|c|c|c|}
\hline \multirow{2}{*}{$\begin{array}{l}\text { Organização do } \\
\text { Livro }\end{array}$} & \multicolumn{2}{|c|}{$\begin{array}{l}\text { Os capítulos não têm abordagem temática porque o contexto social não é trabalhado de } \\
\text { forma contínua }\end{array}$} \\
\hline & \multicolumn{2}{|c|}{$\begin{array}{l}\text { As seções de abertura não apresentam ASC. Temas ambientais, questões econômicas e } \\
\text { natureza da ciência foram mais citados }\end{array}$} \\
\hline $\begin{array}{l}\text { Texto de } \\
\text { Conteúdo }\end{array}$ & \multicolumn{2}{|c|}{$\begin{array}{l}\text { Todos os capítulos tinham tópicos de relação com temas globais. Os capítulos } 3 \text { a } 6 \text { ti- } \\
\text { nham possiblidades de abordagem ASC nos textos }\end{array}$} \\
\hline \multirow{5}{*}{$\begin{array}{l}\text { Conteúdo dos } \\
\text { boxes e atividades }\end{array}$} & Pare e pense: não aborda ASC & $\begin{array}{l}\text { Construção do conhecimento: não aborda } \\
\text { ASC }\end{array}$ \\
\hline & $\begin{array}{l}\text { Atividade experimental: sem potencial para } \\
\text { discussão de ASC }\end{array}$ & $\begin{array}{l}\text { História da ciência: sem potencial para dis- } \\
\text { cussão de ASC }\end{array}$ \\
\hline & $\begin{array}{l}\text { Revisão para a prova: sem potencial para } \\
\text { discussão de ASC }\end{array}$ & $\begin{array}{l}\text { Atitude sustentável: sem potencial para } \\
\text { discussão de ASC }\end{array}$ \\
\hline & $\begin{array}{l}\text { Participação cidadã: geralmente aborda } \\
\text { ASC, mas não está presente em todos os } \\
\text { capítulos }\end{array}$ & Ação e cidadania: nem sempre aborda ASC. \\
\hline & $\begin{array}{l}\text { Tomada de decisão: sempre aborda ASC, } \\
\text { mas não está presente em todos os capí- } \\
\text { tulos }\end{array}$ & $\begin{array}{l}\text { Exercícios: sem potencial para discussão } \\
\text { de ASC }\end{array}$ \\
\hline
\end{tabular}

Fonte: autoria própria, a partir de Santos e Mól (2016) 
Livro 4: Lisboa (2016)

O quadro 10 sumariza as principais características das seções do livro 4, frente aos critérios de categorização. Após a etapa de análise aprofundada, foi novamente verificado o acerte em propor a tipificação debate como melhoria dos tipos considerados inicialmente. Na obra, encontrou-se os seguintes exemplos de atividades ASC:

- Página 100: No item “CTS" da seção de encerramento (capítulo 4, unidade 2), os alunos são convidados a debater sobre a coerência entre as regras estipuladas na lei seca frente ao comportamento do etanol no organismo, indicando uma atividade que possibilita discussão ASC por meio de questionamento, pois aborda a formação de opiniões, baseada em valores e no conhecimento científico, sendo amplamente divulgado pela mídia, que envolve a análise de risco.

- Página 187: No item "CTS" da seção de encerramento (capítulo 9, unidade 3), encontra-se uma atividade que prevê o debate sobre questões econômicas e sociais frente a substituição do petróleo em função de seus impactos ambientais e relações econômicas. Considerou-se uma atividade potencialmente promotora de discussão sociocientífica por meio de questionamentos, pois aborda a formação de opiniões, baseada em valores e no conhecimento científico, sobre um problema global, amplamente divulgado pela mídia, de cunho sustentável e que envolve a análise de custo-benefício e de risco.

- Página 218: No item “CTS" da seção de encerramento (capítulo 10, unidade 3) é proposta a discussão sobre a importância de ações de geração de renda em relação à reciclagem de óleo para a produção de sabão. Foi considerada uma atividade promotora de discussão sociocientífica, pois aborda a formação de opiniões, baseada no conhecimento científico, de cunho sustentável e que envolve a análise de custo-benefício. 
Quadro 10: Análise aprofundada do Livro 4

\begin{tabular}{|c|c|c|}
\hline \multirow{2}{*}{$\begin{array}{l}\text { Organização do } \\
\text { Livro }\end{array}$} & \multicolumn{2}{|c|}{$\begin{array}{l}\text { As unidades são divididas de acordo com o conteúdo químico. As seções de abertura não } \\
\text { trazem elementos que permitem empregar ASC }\end{array}$} \\
\hline & \multicolumn{2}{|c|}{$\begin{array}{l}\text { Os capítulos são organizados de acordo com o conteúdo químico e não fornecem elemen } \\
\text { tos para discussão ASC. Com exceção dos capítulos } 4,9 \text { e } 10\end{array}$} \\
\hline $\begin{array}{l}\text { Texto de } \\
\text { Conteúdo }\end{array}$ & \multicolumn{2}{|c|}{$\begin{array}{l}\text { O texto de conteúdo não apresenta questionamentos que levem à discussão ASC, apenas } \\
\text { pergunta para averiguar o conhecimento prévio dos alunos }\end{array}$} \\
\hline \multirow{5}{*}{$\begin{array}{l}\text { Conteúdo dos } \\
\text { boxes e atividades }\end{array}$} & $\begin{array}{l}\text { Saiba mais: sem potencial para discussão } \\
\text { de ASC }\end{array}$ & Química tem história: não aborda ASC \\
\hline & $\begin{array}{l}\text { Você se lembra: sem potencial para dis- } \\
\text { cussão de ASC }\end{array}$ & $\begin{array}{l}\text { Ação e cidadania: embora apresentem } \\
\text { contextualização, não aborda ASC }\end{array}$ \\
\hline & $\begin{array}{l}\text { Química e...: embora apresentem contex- } \\
\text { tualização, sem potencial para discussão } \\
\text { de ASC }\end{array}$ & $\begin{array}{l}\text { Atividades: sem potencial para discussão } \\
\text { de ASC }\end{array}$ \\
\hline & $\begin{array}{l}\text { Enem e Vestibular: sem potencial para } \\
\text { discussão de ASC }\end{array}$ & $\begin{array}{l}\text { Ciência, Tecnologia e Sociedade: apresen- } \\
\text { ta contextualização nos capítulos } 4,9 \text { e } 10 \\
\text { que podem levar à discussão de ASC }\end{array}$ \\
\hline & $\begin{array}{l}\text { Atividade experimental: sem potencial para } \\
\text { discussão de ASC }\end{array}$ & $\begin{array}{l}\text { Projeto: não aborda ASC, embora possam } \\
\text { ser considerados contextualizados. }\end{array}$ \\
\hline
\end{tabular}

Fonte: autoria própria, a partir de Lisboa (2016)

Livro 5: Ciscato et al. (2016)

O quadro 11 sumariza as principais características das seções do livro 5 frente aos critérios de categorização. Este foi o único livro no qual não foram encontrados trechos que pudessem ser considerados como promotores de discussão controversa, por não estabelecerem claramente questionamentos, textos ou temas de caráter controverso.

\section{Quadro 11: Análise aprofundada do Livro 5}

\begin{tabular}{|c|c|c|}
\hline \multirow[t]{2}{*}{$\begin{array}{l}\text { Organização do } \\
\text { Livro }\end{array}$} & \multicolumn{2}{|c|}{$\begin{array}{l}\text { O livro se organiza por temas de contextualização, a seção de abertura da unidade é } \\
\text { bastante contextualizada, mas nunca controversa. Os trabalhos em grupo são mais } \\
\text { passiveis de ASC }\end{array}$} \\
\hline & \multicolumn{2}{|c|}{ Os temas são organizados por conteúdos que não permitem ASC } \\
\hline Texto de Conteúdo & \multicolumn{2}{|c|}{$\begin{array}{l}\text { O texto de conteúdo não apresenta questionamentos que levem à discussão ASC, } \\
\text { apenas pergunta para averiguar o conhecimento prévio dos alunos }\end{array}$} \\
\hline \multirow{3}{*}{$\begin{array}{l}\text { Conteúdo dos } \\
\text { boxes e atividades }\end{array}$} & $\begin{array}{l}\text { Box genérico: sem potencial para discus- } \\
\text { são de ASC }\end{array}$ & $\begin{array}{l}\text { Glossário: sem potencial para discussão } \\
\text { de ASC }\end{array}$ \\
\hline & $\begin{array}{l}\text { Atividade prática: sem potencial para } \\
\text { discussão de ASC }\end{array}$ & $\begin{array}{l}\text { Questões para fechamento do tema: sem } \\
\text { potencial para discussão de ASC }\end{array}$ \\
\hline & $\begin{array}{l}\text { Exercícios finais: sem potencial para dis- } \\
\text { cussão de ASC }\end{array}$ & $\begin{array}{l}\text { Atividades em grupo: sempre contextuali- } \\
\text { zadas, mas não aborda ASC }\end{array}$ \\
\hline
\end{tabular}

Fonte: autoria própria, a partir de Ciscato et al. (2016) 


\section{Livro 6: Novais e Antunes (2016)}

O quadro 12 sumariza as principais características das seções do livro 6 frente aos critérios de categorização, baseado nos exemplos de fragmentos com características de ASC retirados do material:

- Página 30: No box Conexões (capítulo 1, unidade 1), é proposto um debate sobre o papel das mulheres na ciência e na sociedade e maneiras de combater a discriminação de gênero. Por isso, foi considerada uma atividade com potencial de promoção de ASC, pois aborda a formação de opiniões, baseada em valores, sobre um problema global, amplamente divulgado pela mídia.

- Página 133: Nas atividades do capítulo 4 (unidade 2) é proposto um debate sobre o consumo social de álcool e a legislação sobre a lei seca em relação ao comportamento social e à saúde humana. A atividade foi considerada com potencial de discussão controvertida por meio de questionamentos, pois aborda a formação de opiniões, baseada em valores e no conhecimento científico, sobre um problema global, amplamente divulgado pela mídia, que envolve a análise de risco.

Quadro 12: Análise aprofundada do Livro 6

\begin{tabular}{|c|c|c|}
\hline \multirow{2}{*}{$\begin{array}{l}\text { Organização do } \\
\text { Livro }\end{array}$} & \multicolumn{2}{|c|}{$\begin{array}{l}\text { A divisão dos capítulos é feita baseada fortemente nos conceitos científicos abordados, } \\
\text { não apresentando laços estreitos com temas globais }\end{array}$} \\
\hline & \multicolumn{2}{|c|}{$\begin{array}{l}\text { Os principais temas foram saúde e população, questões econômicas e temas ambien- } \\
\text { tais. A possibilidade de ASC foi encontrada nos capítulos } 1 \text { e } 4\end{array}$} \\
\hline Texto de Conteúdo & \multicolumn{2}{|c|}{$\begin{array}{l}\text { O conteúdo é apresentado em formato de texto corrido complementado pelas informa- } \\
\text { ções dos boxes. Há questionamento, porém nunca controversos }\end{array}$} \\
\hline \multirow{5}{*}{$\begin{array}{l}\text { Conteúdo dos } \\
\text { boxes e atividades }\end{array}$} & $\begin{array}{l}\text { Para situá-lo: sem potencial para discus- } \\
\text { são de ASC }\end{array}$ & $\begin{array}{l}\text { Boxes: textos pequenos, sem perguntas, } \\
\text { sem potencial para discussão de ASC }\end{array}$ \\
\hline & $\begin{array}{l}\text { Química: prática e reflexão: Experimen- } \\
\text { tos e questões voltadas aos conceitos } \\
\text { químicos exclusivamente }\end{array}$ & $\begin{array}{l}\text { Atividades: sem potencial para discussão de } \\
\text { ASC }\end{array}$ \\
\hline & $\begin{array}{l}\text { Viagem no tempo: não aborda ASC, ex- } \\
\text { ceto no capítulo } 2\end{array}$ & $\begin{array}{l}\text { Testando seus conhecimentos: sem poten- } \\
\text { cial para discussão de ASC }\end{array}$ \\
\hline & $\begin{array}{l}\text { Conexões: possibilidade de abordagem } \\
\text { ASC no capítulo } 1\end{array}$ & $\begin{array}{l}\text { Resgatando o que foi visto: sem potencial } \\
\text { para discussão de ASC }\end{array}$ \\
\hline & \multicolumn{2}{|c|}{ Atividade de encerramento do capítulo: possibilidades de ASC no capítulo 4} \\
\hline
\end{tabular}

Fonte: autoria própria, a partir de Novaes e Antunes (2016) 


\section{Análise geral das obras}

Diante dos resultados das unidades de contexto, é possível afirmar que a coleção "Química" (REIS, 2016), no conjunto dos três volumes, apresenta poucos elementos relacionados a ASC, em sua maioria abordados por questionamentos que não são tratados no livro de forma completa. Foram observados casos de abordagem temática no início de algumas seções, mas a discussão de ASC não foi estimulada do conjunto do livro. É possível verificar a presença de perguntas isoladas que poderiam ser motivadores da discussão ASC, mas sem o embasamento no restante da obra. Infere-se que um professor adotante dessa obra não tenha elementos suficientes para abordar ASC. Para a composição desta análise geral, foram empregados os dados da análise dos livros destinados à primeira série apresentado em artigo anterior (OS AUTORES).

Considerando os três volumes da coleção "Química" (MORTIMER; MACHADO, 2017), é possível perceber que a obra apresenta poucos elementos relacionados a ASC, em sua maioria abordados por questionamentos que não são tratados no livro de forma completa. O livro apresenta abordagem fortemente marcada pelo estudo centrado no conceito científico, não explorando em profundidade questões concernentes aos ASC, embora haja relação com contextualização com temas globais.

Foi possível concluir, após a análise dos três volumes da coleção "Química Cidadã" (SANTOS; MÓL, 2016), que esta se propõe a discutir ASC e é possível observar a presença de tomadas de decisão de debates de maneira pontual e por questionamentos em boxes separados. O texto de conteúdo traz tópicos de contextualização social que poderia suscitar a discussão de ASC, mas não são apresentadas controvérsias no texto. Em alguns casos, as atividades poderão tornar-se discussões de ASC ou apenas informações.

Levando em consideração as análises dos três volumes da coleção "Ser Protagonista - Química" (LISBOA, 2016), percebe-se que o livro não apresenta subsídios para a discussão de ASC, traz poucos elementos potencialmente controversos e poucas vezes aborda temas que podem ser, se conduzidos pelo professor, discutidos de forma sociocientífica.

A partir da análise aprofundada dos três volumes da coleção "Química" (CISCATO et al., 2016), foi possível estabelecer que apesar do livro ser organizado por temas que levam a contextualização do início ao fim dos capítulos, os momentos que 
teriam maior potencial ASC permitem apenas abordagem pontual. O conteúdo em si apresenta-se desconectado de problemáticas sociocientíficas.

Com base nas análises aprofundadas dos volumes da coleção "Vivá - Química" (NOVAIS; ANTUNES, 2016) é possível observar que a obra apresenta poucos elementos relacionados a ASC, em sua maioria abordados por questionamentos que não são tratados no livro de forma completa. Foi observado um novo tema que poderia ser considerado: o uso da linguagem científica vs. comum. A obra em si não sustenta a discussão, que deveria ser fomentada pelo professor.

Além disso, é possível perceber que, em termos de fragmentos ASC, as obras dos mesmos autores não são semelhantes em relação a frequência desses trechos, pois observa-se uma diminuição da presença de elementos potenciais da primeira para a segunda e da segunda para a terceira série na maioria dos casos, exceto no livro "Ser Protagonista - Química" (LISBOA, 2016) que, embora apresente diminuição de articulação com temas globais na terceira série, apresenta mais fragmentos com potencial ASC nesta série.

Outro ponto importante é a articulação com temas globais que também é diferente entre obras de mesmos autores, em diferentes séries, e em diferentes obras para a mesma série. Infere-se que esta constatação evidencia ainda mais a importância em se empreender processos intencionais e cuidadosos de escolha de livros didáticos pelos docentes.

Por fim, foi possível evidenciar que a obra Química Cidadã (SANTOS; MÓL, 2016), como esperado, é a que apresenta maior incidência de temas globais e fragmentos que podem conduzir a uma abordagem ASC em sala de aula. As obras "Química" (REIS, 2016) e "Vivá - Química" (NOVAIS; ANTUNES, 2016) apresentaram similaridade quanto a quantidade de elementos relacionados a temas globais e potencial ASC em cada série, assim como o tipo de abordagem.

\section{Considerações finais}

A análise das obras é extremamente importante para apresentar potencialidades para a abordagem ASC em livros didáticos do ensino médio, bem como para a divulgação aos professores sobre quais volumes ou obras possuem mais fragmentos com potencial de discussão de ASC. Inicialmente, os autores analisaram os volumes das primeiras séries do ensino médio, inferindo que, embora todas as obras tenham 
apresentado fragmentos com potencial de fomentar a discussão sociocientífica, os livros não trazem todas as informações necessárias para a discussão controvertida (OS AUTORES). Além disso, constatou-se a necessidade de aumentar a quantidade de temas de contexto e tipos de abordagem para abarcar os exemplos contidos nos livros. Posteriormente, para a análise dos volumes da segunda e terceira séries do ensino médio, foi confirmada a importância da inclusão dos elementos sugeridos na etapa anterior, como novos temas globais e tipos de controvérsia, sendo estes relevantes para a classificação dos livros.

Em geral, a análise dos livros da segunda série do ensino médio apresentou menos fragmentos com potencial de abordagem ASC. Esta percepção pode estar relacionada aos conteúdos químicos abordados. Infelizmente, os conteúdos de físico-química parecem reduzir as inserções de ASC, embora os autores acreditem que eles podem ser trabalhados com a mesma abordagem. Para exemplificar, podem ser relacionadas questões sobre a escolha de combustíveis com base em seu calor de combustão, problematizar os tipos de materiais empregados em pilhas e seu impacto ambiental e possibilidades de reciclagem ou ainda, compreender a utilização de estabilizantes químicos para o aumento da vida de prateleira de alimentos com base na cinética de degradação.

À guisa de consideração das coleções, é possível perceber que, de certa forma, a maioria as obras tem algum potencial de fomentar discussões ASC em sala de aula, mas que os livros não trazem todos os elementos necessários para que a discussão da controvérsia se desenvolva, fato que dependerá dos professores e alunos. Como o esperado, a obra com maior incidência, ainda que não na maioria de suas unidades de contexto, é a obra Química Cidadã (SANTOS; MÓL, 2016) por ser construída nessa abordagem. Espera-se que este estudo contribua para reflexão dos professores de Química no momento de escolha dos livros didáticos aprovados pelo PNLD.

Este estudo, considerando a classificação de todas aos 18 obras (vide OS AUTORES) ainda contribuiu para melhorar os trabalhos usados como referencial no que diz respeito aos temas de relevância, ao aumentar o rol de possibilidades a partir dos temas globais apresentados por Merryfield (1991 apud SANTOS, 2002) para materiais de larga escala. E na tipificação da controvérsia apresentada por Stadler (2005), apresentando mais possibilidades de atividades envolvendo a abordagem de ASC e como continuação deste trabalho, os professores do LADIEC pretendem estender essa análise a livros de Biologia e Física, integrantes da área 
de Ciências da Natureza, além da avaliar a possibilidade deste tipo da abordagem em sala de aula.

\section{Analysis of socio-scientific issues in chemistry textbooks used in high school}

\section{Abstract}

The investigation of distinct possibilities of using the textbook in the classroom occurs for the importance of this didactic resource, promoted by the National Textbook Program (PNLD). The approach of Socio-scientific Aspects (ASC), among the various conceptions of teaching Chemistry, uses a contextualization based on socially relevant themes mobilized by the discussion of controversies, based on scientific knowledge. Thus, investigating ASC in Chemistry textbooks can help teachers to use this teaching concept. It centered this research on the analysis of books of special Chemistry to the second and third grade of high school by PNLD. The method used was a content analysis based on the indicators: global theme, presence of controversy and classification criteria to classify the texts in potential promoters of socio-scientific case. Subsequently, the approach and the controversy oriented were delimited. An analysis of high school second grade books showed few fragments with the potential for ASC approach. In addition, it is possible to observe that most works have some potential to promote ASC in the classroom, but the books do not provide all the basic elements for the discussion of the controversy to develop, a fact that will depend on teachers and students. As expected, the work with the highest incidence, although not in most of its context units, is the work "Química Cidadã", for being built on this approach.

Keywords: Socio-scientific issues; Textbooks, PNLD, Science Teaching.

\section{Referências}

BARDIN, Lawrance. Análise de Conteúdo. Lisboa: Edições 70, 2011.

BRASIL. Lei № 9.394 de 20 de dezembro de 1996. Estabelece as diretrizes e bases da educação nacional, Brasília, 1996.

BRASIL. Base Nacional Comum Curricular. Brasília: MEC, 2017. Disponível em: http://basenacionalcomum.mec.gov.br/images/BNC C_20dez_site.pdf. Acesso em: 22 de dezembro de 2017.

BRASIL. PNLD 2018: apresentação - guia de livros didáticos - ensino médio/ Ministério da Educação - Secretária de Educação Básica - SEB - Fundo Nacional de Desenvolvimento da Educação. Brasília, DF: Ministério da Educação, Secretária de Educação Básica, 2017.

CISCATO, Carlos Alberto Mattoso; et al. Química. São Paulo: Moderna, 2016

DELIZOICOV, Demétrio, ANGOTTI, José André, PERNAMBUCO, Marta Maria. Ensino de Ciências: fundamentos e métodos. São Paulo: Cortez, 2018. 
FERNANDES-SOBRINHO, Marcos. Temas sociocientíficos no Enem e no livro didático: limitações e potencialidades para o ensino de Física. Brasília: UnB. Tese de Doutorado em Educação. Universidade de Brasília, 2014.

FRACALANZA, Hilário. O que sabemos sobre os livros didáticos para o ensino de ciências no Brasil. Campinas: Unicamp. Tese de doutorado em Educação. Faculdade de Educação, Universidade de Campinas, 1992.

GIL, Antônio Carlos. Como elaborar projetos de pesquisa. São Paulo: Atlas, 2010.

HALMENSCHLAGER, Karine Raquiel, DELIZOICOV, Demétrio. Abordagem Temática no Ensino de Ciências: Caracterização de Propostas Destinadas ao Ensino Médio. Alexandria: R. Educ. Ci. Tec., v.10, n. 2, p. 305-330, 2017,

LISBOA, Julio César Foschini. Ser Protagonista - Química. São Paulo: SM, 2016.

MERRYFIELD, Merry Marc. Science-technology-society and global perspectives. Theory into Practice, v. 30, n. 4, p. 288-293, 1991.

MORTIMER, Eduardo Fleury, MACHADO, Andréa Horta. Química. São Paulo: Scipione, 2017.

NETO, Jorge Megid; FRACALANZA, Hilário. O Livro Didático de Ciências: Problemas e Soluções. Ciência \& Educação, v. 9, n. 2, p. 147-157, 2003.

NOVAIS, Vera Lúcia Duarte; ANTUNES, Murilo Tissoni. Vivá: Química. Curitiba: Positivo, 2016.

PÉREZ, Leonardo Fabio Martinez; CARVALHO, Washington Luiz Pacheco. Contribuições e dificuldades da abordagem de questões sociocientíficas na prática de professores de ciências. Educação e Pesquisa, v. 38, n. 3, p. 727-741, 2012.

REIS, Martha. Química. São Paulo: Ática, 2016.

SANTOS, Wildson Luiz Pereira. Aspectos sociocientíficos nas Aulas de Química. Belo Horizonte: UFMG. Tese de Doutorado em Educação. Faculdade de Educação, Universidade Federal de Minas Gerais, 2002.

SANTOS, Wildson Luiz Pereira, MÓL, Gerson. Química Cidadã. São Paulo, AJS, 2016.

SANTOS, Wildson Luiz Pereira, MORTIMER, Eduardo Fleury. Abordagem de Aspectos sociocientíficos nas aulas de Ciências: Possibilidades e Limitações. Investigações no Ensino de Ciências, v. 14, n. 2, p. 191-218, 2009.

STADLER, João Paulo. Análise de aspectos sociocientíficos em questões de Química do Enem: subsídio para a elaboração de material didático para a formação cidadã. Curitiba: UTFPR. Dissertação de Mestrado em Formação Científica, Educacional e Tecnológica, Universidade Tecnológica Federal do Paraná, Curitiba. 